\section{Herança e promessas do ensino das Ciências Sociais na área da Saúde}

\author{
Legacy and promises from the teaching of Social \\ Sciences in the health field
}

\author{
1 Escola Nacional de Saúde \\ Pública Sergio Arouca, \\ Fundação Oswaldo Cruz, \\ Rio de Janeiro, Brasil. \\ Correspondência \\ M. C. S. Minayo \\ Centro Latino-Americano de \\ Estudos de Violência e Saúde \\ Jorge Careli, Escola Nacional \\ de Saúde Pública Sergio \\ Arouca, Fundação Oswaldo \\ Cruz. \\ Av. Brasil 4036, Rio de \\ Janeiro, $R J$ \\ 21040-361, Brasil. \\ cecilia@claves.fiocruz.br
}

\begin{abstract}
The article analyzes the teaching and learning of Social Sciences in Health Sciences courses from the perspective of the curriculum and learning generated by research groups and thesis supervision activities. The author conducts a rereading of the classics and main contemporary scientists, based on the subarea's scientific output and her own personal experience as professor, researcher, and thesis supervisor. The article focuses on the tradition and teaching of the classics in Social Sciences, the main contemporary social theories, social sciences in health with an emphasis on teaching, and observations on the interface between teaching in Social Sciences and Life Sciences. The author concludes by highlighting the importance of work by social scientists in the health field and identifies the following problematic points: difficulties in dealing with mediations between the biological and the social; frequent subordination of foundations to techniques; and ideological and common-sense issues in the teaching and appropriation of Social Sciences in Health.
\end{abstract}

Social Sciences; Health; Teaching
Maria Cecília de Souza Minayo ${ }^{1}$

\section{Introdução}

Este artigo trata do ensino das Ciências Sociais como legado ${ }^{1}$ que os profissionais desta área trazem para a compreensão, os cuidados, as políticas, a gestão e a avaliação do setor saúde. Tenho como pano de fundo, não apenas o ensino desenvolvido em sala de aula, como também a interação e a criação de conhecimento que ocorrem nos grupos de pesquisa e nas orientações dos estudantes.

Parto de algumas premissas: (1) indissociabilidade entre pesquisa e ensino; (2) visão intersubjetiva de ensino/aprendizagem, segundo a qual tanto o professor como o estudante são aprendizes; (3) o fato das Ciências Sociais em Saúde não constituírem um campo de conhecimento autônomo e, sim, um subcampo.

Com base nessas premissas, ressalto que o ensino das Ciências Sociais na área da saúde não pode prescindir de uma incursão sobre o campo do qual faz parte, embora observando-se sua especificidade. Neste texto, serão destacados: (1) a tradição e os clássicos; (2) as teorias sociais na atualidade; (3) o ensino das Ciências Sociais no campo da saúde; e (4) observações sobre a associação entre o ensino das Ciências Sociais e das biomédicas.

Além da releitura dos clássicos, este artigo se apoia na produção científica da subárea e, inclusive, na minha experiência pessoal como professora e orientadora. Cito a seguir alguns dos 
instituintes desse subcampo: Donnangelo et al. 2; Nunes 3,4,5,6; Nunes et al. 7,8,9; Canesqui 10; Luz 11; Loyola 12; Cohn \& Nunes 13; Marsiglia 14; Alves 15; Minayo 16,17; Bodstein 18; Gomes \& Goldenberg 19; Coimbra Jr. Santos 20; Minayo-Gomez \& ThedimCosta 21 e outros não mencionados pela exiguidade do espaço.

\section{Por que Ciências Sociais e não disciplinas?}

Todo ramo do saber possui três modos de se apresentar: campos disciplinares; estruturas corporativas; e comunidade de estudiosos. Disciplinas são construções intelectuais a partir de uma região particular do conhecimento que apresentam teoria, métodos e fronteiras próprias e definem o que se pensa, como se pensa, o que se ensina e o que não é de sua competência. A sociologia, por exemplo, foi uma invenção do final do século XIX. Nesse período, todas as divisões das Ciências Sociais se estabeleceram. Mas, as mudanças ocorridas no mundo pós 1945 derrubaram a lógica da segmentação, diluíram fronteiras e aproximaram abordagens teórico-metodológicas e o ensino das várias disciplinas.

As denominações disciplinares, porém, continuaram a existir, pois se já não podem ser defendidas do ponto de vista epistemológico, continuam institucionalizadas como formas de poder 22,23 corporativo, nos departamentos, nos programas de ensino, nos congressos científicos, nos periódicos e nas classificações bibliográficas.

\section{A herança dos clássicos}

Não se pode ensinar Ciências Sociais sem se valer da importante colaboração de três grandes pilares históricos do campo: Durkheim, Marx e Weber. Data da metade do século XX o seu reconhecimento como clássicos 1 . Wallerstein 1 atribui a Talcott Parsons 24 o empenho em demonstrar Durkheim e Weber no papel de instituintes das Ciências Sociais e comenta que, apesar de sua tentativa de excluir Marx dessa tríade, a presença desse autor se impôs pela importância de sua contribuição.

O legado de Durkheim - o único que se autodenominou sociólogo, empenhado em tornar a sociologia uma ciência tão importante quanto a biologia e a física - pode se resumir na tese geral de que a sociedade possui estruturas, leis e normas explicáveis, cujos princípios são: (1) os fatos sociais devem ser tratados como coisas e externos aos indivíduos; (2) a sociedade existe pela internalização das normas que cria e pelas representações coletivas que exercem coerção sobre os indivíduos; (3) os indivíduos interagem segundo crenças e comportamentos instituídos e compartilhados pela coletividade. Assim como todos os clássicos, Durkheim desenvolveu um método associado à teoria que construiu, estabeleceu regras para seu uso e realizou estudos empíricos utilizando-o.

A contribuição principal de Marx é a tese de que a história de toda a sociedade se baseia na luta entre as classes. Enquanto Durkheim ressalta as regularidades dos fatos sociais, Marx traz para o campo uma pergunta fundamental sobre como as sociedades se transformam. Seu axioma básico é que nelas os grupos se formam por oposição segundo interesses; a dominação preside as relações sociais hierarquicamente organizadas; e as mudanças ocorrem a partir dos conflitos e das contradições. O materialismo histórico é o cerne de sua teoria e o método dialético, desenvolvido e utilizado por ele para compreender e interpretar a realidade social.

Weber enfatizou o papel do indivíduo na história e inaugurou a teoria da ação social, respondendo a uma pergunta fundamental das Ciências Sociais: por que as sociedades, com tantos interesses em jogo, não se despedaçam e se destroem? Sua contribuição original é o conceito de legitimidade como fundamento dos vários tipos de autoridade que existiram ao longo da história ou persistem simultaneamente na atualidade (a tradicional, a carismática e a burocrática). Weber propõe o modelo do tipo-ideal como abordagem metodológica criada e utilizada por ele.

\section{O papel dos cientistas sociais contemporâneos}

Existem controvérsias sobre a reverência aos clássicos das Ciências Sociais, o que não ocorre nas ciências naturais 25 . Nesse debate, diferentes autores $1,25,26,27$, ao mesmo tempo em que os valorizam, chamam atenção para a necessidade de criação de uma nova cultura aberta que privilegie as Ciências Sociais reunificadas dentro de um mundo do conhecimento epistemologicamente mais complexo e de fronteiras diluídas.

A evocação dessa abertura parte da constatação sobre as mudanças ocorridas no mundo pósSegunda Guerra Mundial, acentuadas depois dos anos 1989 - cujo símbolo é a queda do Muro de Berlim. Assim, nascidos na Europa ao final do século XIX, os marcos teóricos e filosóficos das Ciências Sociais se tornaram insuficientes por causa da hegemonia econômica, cultural e científica dos Estados Unidos; do ressurgimento polí- 
tico do mundo ocidental; da internacionalização da economia; do afrouxamento das fronteiras entre Estado, Sociedade Civil e Mercado; da crise do petróleo a partir da qual expandiu-se o movimento ambientalista; do movimento cultural por direitos das mulheres, dos grupos etários e étnicos e de segmentos sociais específicos como homossexuais e portadores de deficiência.

É relevante assinalar que ciência e tecnologia se tornaram as grandes protagonistas da maioria das inovações e retornam como desafios para seus campos específicos. É o caso do incomparável desenvolvimento da microeletrônica, das áreas de informação e comunicação e da biologia. A interação entre o conhecimento gerado, os artefatos construídos e a globalização da economia, da cultura e das comunicações coloca novas questões para as Ciências Sociais, criadas dentro da lógica do Estado-Nação e da sociedade industrial.

Por que falar de temas tão amplos, como os citados no parágrafo anterior, num texto que deveria se restringir ao ensino das Ciências Sociais? A resposta a essa indagação tem eco nos mais respeitados cientistas sociais. A maioria reconhece a contribuição dos clássicos e o faz demonstrando que muitos dos problemas centrais das Ciências Sociais continuam os mesmos 1,25,26,27, mas, ressalta que tê-los em conta não significa tratá-los como mitos e, suas palavras, como dogmas. Assim, é preciso reafirmar que ensinar os clássicos é aprofundar e ampliar as perguntas que fizeram, e nunca limitar o estudo sobre eles a uma mera e estéril exegese, ainda que erudita. Nesse sentido, alguns assuntos sobressaem na atualidade:

(a) necessidade de relativizar as bases de uma ciência social centrada no pensamento e na cultura ocidental quando no mundo, as culturas africanas, árabes e orientais retomam seu poderio e protagonismo como lembra Wallerstein em Análise dos Sistemas Mundiais 28;

(b) importância de aprofundar o significado dos novos conceitos de tempo e espaço (categorias centrais do pensamento humano, segundo Weber 29) que presentificam simultaneamente várias realidades sociais e vários tempos históricos - conjunturas, longa e muito longa duração. As aceleradas transformações nos campos da comunicação e da informação concomitantemente produzem profundas mudanças culturais;

(c) adesão à contribuição do feminismo para as teorias e a epistemologia das Ciências Sociais, uma vez que esse movimento veio evidenciar tanto o machismo no pensamento, na organização e na distribuição do poder no campo científico (inclusive nas Ciências Sociais) como contribuir com métodos participativos de análise da realidade social, baseados na categoria "gênero"; (d) incorporação da contribuição do movimento ambientalista que não só desbancou o antropocentrismo típico da sociedade industrial, mas vem evidenciando o peso da ação humana na degradação da natureza. A presença dos cientistas sociais na reflexão sobre a questão ambiental é crucial para as reflexões e análises que envolvem todos os agentes dos problemas (sociais, de saúde e ecológicos) e das soluções 30;

(e) importância de aprofundar as novas teorias da complexidade que vêm da biologia, da química e da física 1. Alguns cientistas sociais vêm incorporando tais aportes, sendo o trabalho mais substancial o do cientista social Niklas Luhamn ${ }^{31}$. Nesse sentido, é preciso atentar para a contribuição da cibernética de segunda ordem que focaliza a interação entre sujeito e objeto, a complexidade dos fenômenos, a organização dos sistemas vivos e dos processos de mudanças por auto-organização, colocando os sistemas sociais e políticos em seu ápice. Essas abordagens exigem superação teórica do estruturalfuncionalismo;

(f) urgência da incorporação de análises sociais sobre as novas tecnologias trazidas pelas descobertas da biologia e seu uso, pois elas modificam os conceitos reprodutivos, de vida, de morte, de vários tabus culturais e repercutem nos processos tradicionais de análise de saúde e doença;

(g) necessidade de aprofundar a contribuição dos vários tipos de teorias da ação hoje em voga. Embora emanadas do pensamento de Weber, muitas delas são até conflitantes: o interacionismo simbólico 32; a etnometodologia 3,7; a sociologia do cotidiano; a teoria da ação dos atores coletivos 23; a fenomenologia sociológica 33; o construtivismo estruturalista 23 ; a teoria da estruturação e da reflexividade social 34; a ação comunicativa 35; a história social 36; a arqueologia do saber 37. É importante ressaltar que nenhum dos autores citados se filia ao pensamento de apenas um dos clássicos. Sua livre incursão pelos fundamentos das Ciências Sociais como um todo os leva a novas perspectivas e muitos poderiam ser tratados como "clássicos contemporâneos".

Em resumo, é impossível ensinar Ciências Sociais em qualquer área hoje sem fazer uma reflexão interativa com os estudantes sobre se e em que sentido as Ciências Sociais vêm dando conta de responder às questões contemporâneas.

\section{Sobre o ensino das Ciências Sociais e Saúde}

Não pretendo aqui repetir o que vem sendo estudado, sobretudo, pelo nosso "clássico" Everardo 
Duarte Nunes, e por outros autores também relevantes, quanto à história e às práticas de ensino das Ciências Sociais no campo ampliado das ciências da saúde. Prefiro reafirmar alguns pontos consensuais entre todos:

(1) a compreensão de que os processos saúde/doença, a organização do setor, as políticas do Estado e governamentais em suas relações com a sociedade e o controle social devem ser analisados e ensinados a partir dos marcos teóricos das Ciências Sociais em seu sentido mais genuíno;

(2) o fato de que algumas correntes de pensamento historicamente tiveram predomínio no ensino das Ciências Sociais em saúde: o estrutural-funcionalismo por meio da reprodução da ideia de "ciências da conduta" proveniente dos Estados Unidos 5, suplantada pela hegemonia do marxismo em suas correntes althusseriana, histórico-estrutural e gramsciana, nesta ordem; e mais recentemente, o hegemônico florescimento das teorias compreensivas em suas várias modalidades;

(3) o reconhecimento de que as teorias da complexidade, que se fundamentam num novo tipo de teoria sistêmica $31,38,39,40$, embora ainda pouco ensinadas, começa a fundamentar estudos que articulam saúde e ambiente, ou tratam da família ou de temas como a violência;

(4) a certeza de que as Ciências Sociais vêm contribuindo para a fundamentação teórica e crítica das demais áreas de saúde;

(5) o crescimento das abordagens interdisciplinares em que as Ciências Sociais fazem dialogar seus conceitos com os de outras áreas do conhecimento.

\section{Crítica na própria carne}

O fato de as Ciências Sociais se associarem ao campo da saúde traz algumas consequências. Muitas benéficas para o aprofundamento do sentido e da historicidade dos conceitos e da crítica intersubjetiva, outras problemáticas como algumas que enumero na finalização deste texto:

(1) nas relações entre as ciências da saúde e as Ciências Sociais permanece a tendência de submeter as segundas às primeiras, considerando- as apenas uma fonte auxiliar do conhecimento biomédico ou das abordagens epidemiológicas e de gestão;

(2) por sua vez, muitos cientistas sociais sentem dificuldades de compreensão da lógica biomédica e de posicionar sua contribuição. É comum encontrá-los insatisfeitos e deslocados em programas de ciências da saúde. Entrar numa área que não é sua e contribuir efetivamente exige consistência na formação e abertura para entender as mediações entre o biológico e o social. Pesquisar e ensinar levando em conta os dois campos é um desafio que pode ser mais bem vencido quando ambos os lados trabalham juntos. Quem já viveu a experiência colaborativa sabe das dificuldades e também do enriquecimento mútuo que daí pode surgir;

(3) embora nos currículos de graduação em ciências da saúde existam disciplinas de Ciências Sociais, elas são pouco valorizadas. Apesar da maioria das doenças estarem associadas a causas sociais e estilos de vida hoje, predomina no ensino a visão clínica e biomédica. Nas pósgraduações, frequentemente, o ensino das Ciências Sociais é oferecido de forma instrumental, favorecendo a dicotomia entre teoria e método, e a simplificação dos fundamentos e da problematização dos objetos 10,41;

(4) pelo fato de quase todo mundo se arvorar em conhecedor da questão social, ainda existe amadorismo no ensino das Ciências Sociais na área de saúde. É muito frequente encontrar orientadores biólogos, médicos e outros ensinando e orientando estudantes em temas sociais, e o fazem dentro da lógica de suas abordagens disciplinares. Também é comum encontrar epidemiologistas e gestores utilizando categorias das Ciências Sociais de forma acrítica e instrumental 39;

(5) Poucos cientistas sociais desenvolvem hoje estudos sobre os movimentos sociais e o controle social no setor ${ }^{17}$. A incorporação desses temas necessariamente abriria caminhos para discussão das forças sociais e seu caráter ativo na configuração da política pública.

Concluindo, as ingentes transformações do mundo contemporâneo trazem novos desafios para que os cientistas sociais possam continuar a considerar a saúde como um dos mais importantes componentes da vida social. 


\section{Resumo}

Problematiza-se o ensino/aprendizagem das Ciências Sociais nos cursos da área de saúde, sob a perspectiva curricular e também da aprendizagem gerada nos grupos de pesquisa e nas atividades de orientação. Para escrever o texto, a autora faz uma releitura dos clássicos e de cientistas contemporâneos de referência, apoia-se na produção científica da subárea e serve-se de sua experiência pessoal como professora, pesquisadora e orientadora. No artigo são destacados: a tradição e o ensino dos clássicos das Ciências Sociais; as principais teorias sociais na atualidade; as Ciências Sociais em saúde com ênfase no ensino; e observações de articulação entre o ensino das Ciências Sociais e das ciências Biomédicas. A autora conclui valorizando a importância do que tem sido realizado pelos cientistas sociais da área e ressalta alguns pontos problemáticos: dificuldades de trabalhar as mediações entre o biológico e o social; frequente relegação dos fundamentos a favor das técnicas; e problemas ideológicos e de senso comum no ensino e apropriação da ciência social em saúde.

Ciências Sociais; Saúde; Ensino

\section{Referências}

1. Wallerstein I. El legado de la sociología, la promesa de la ciencia social. Caracas: Editorial Nueva Ciudad; 1999.

2. Donnangelo MC, Pereira L. Saúde e sociedade. São Paulo: Duas Cidades; 1976

3. Nunes ED. Análise de alguns modelos utilizados no ensino das Ciências Sociais nas escolas médicas: bases teóricas. Rev Saúde Pública 1978; 12:506-15.

4. Nunes ED. Sobre a sociologia da saúde. São Paulo: Editora Hucitec; 1999.

5. Nunes ED. O ensino das Ciências Sociais nas escolas médicas: revisão de experiências. Ciênc Saúde Coletiva 2003; 8:209-25.

6. Nunes ED. Cecília Donnangelo: pioneira na construção teórica de um pensamento social em saúde. Ciênc Saúde Coletiva 2008; 13:909-16.

7. Nunes ED, Ferreto LE, Barros NF. A pós-graduação em Saúde Coletiva no Brasil: trajetória. Ciênc Saúde Coletiva 2010; 15:1923-34.

8. Nunes ED, Nascimento JL, Barros NF. A questão curricular para o plano de formação em Saúde Coletiva: aspectos teóricos. Ciênc Saúde Coletiva 2010; 15:1935-43

9. Nunes ED, Ferreto LE, Oliveira ALO, Nascimento JL, Barros NF, Castellanos MEP. O campo da Saúde Coletiva na perspectiva das disciplinas. Ciênc Saúde Coletiva 2010; 15:1917-22.
10. Canesqui A. Sobre a presença das Ciências Sociais e humanas na saúde pública. Saúde Soc 2011; 20: 16-21.

11. Luz MT. As instituições médicas no Brasil: instituição e estratégia de hegemonia. Rio de Janeiro: Graal; 1978

12. Loyola MAR. A saga das Ciências Sociais na área da Saúde Coletiva: elementos para reflexão. Physis (Rio J.) 2008; 18:251-75.

13. Cohn A, Nunes ED. A pós-graduação em saúde coletiva: mestrado e doutorado. Estudos em Saúde Coletiva 1988; (5):15-26.

14. Marsiglia RMG. Curso de saúde publica em um semestre. Rev Saúde Pública 2006; 40:87-92.

15. Alves PC. A fenomenologia e as abordagens sistêmicas nos estudos sócio-antropológicos da doença: breve revisão crítica. Cad Saúde Pública 2006; 22:1547-54

16. Minayo MCS. O desafio do conhecimento: metodologia de pesquisa social em saúde. Rio de Janeiro: Editora Hucitec; 2010.

17. Minayo MCS. Pós-graduação em Saúde Coletiva de 1997 a 2007: desafios, avanços e tendências. Ciênc Saúde Coletiva 2010; 15:1897-907.

18. Bodstein R. É preciso avançar o pensamento crítico e criativo. Ciênc Saúde Coletiva 2001; 6:30-2. 
19. Gomes MHA, Goldenberg P. Retrato quase sem retoques dos egressos dos programas de pós-graduação em Saúde Coletiva, 1998-2007. Ciênc Saúde Coletiva 2010; 15:1989-2005.

20. Coimbra Jr. CEA, Santos RV. Saúde, minorias e desigualdade: algumas teias de interrelações, com ênfase nos povos indígenas no Brasil. Ciênc Saúde Coletiva 2000; 5:125-32.

21. Minayo-Gomez C, Thedim-Costa SMF. Incorporação das Ciências Sociais na produção de conhecimentos sobre trabalho e saúde. Ciênc Saúde Coletiva 2003; 8:125-36.

22. Bourdieu P. Homo academicus. Paris: Éditions de Minuit; 1984.

23. Bourdieu P. Razões práticas: sobre a teoria da ação. Campinas: Papirus Editora; 1996.

24. Parsons T. The social system. New York: Free Press; 1951.

25. Alexander JC. A importância dos clássicos. In: Giddens A, Turner J, organizadores. Teoria social hoje. São Paulo: Editora Unesp; 1999. p. 23-90.

26. Giddens A, Turner JH. Apresentação. In: Giddens A, Turner JH, organizadores. Teoria social hoje. São Paulo: Editora Unesp; 1999. p. 8-21.

27. Albert H. Tratado da razão crítica. Rio de Janeiro: Tempo Brasileiro; 1976.

28. Wallerstein I. Análise dos sistemas mundiais. In: Giddens A, Turner J, organizadores. Teoria social hoje. São Paulo: Editora Unesp; 1999. p. 447-70.

29. Weber M. Ensaios de sociologia. Rio de Janeiro: Jorge Zahar Editores; 1979.
30. Minayo MCS, Miranda AC. Enfoque ecossistêmico de saúde e qualidade de vida. In: Minayo MCS, Miranda AC, organizadores. Saúde e ambiente sustentável: estreitando nós. Rio de Janeiro: Editora Fiocruz; 2002. p. 209-31.

31. Luhmann N. System as difference. Organization 2006; 13:37-57.

32. Tourain A. Le retour de l'acteur. Paris: Fayard; 1984.

33. Shutz A. Le chercheur et le quotidien. Paris: Méridiens Klinck-Sieck; 1987.

34. Giddens A. La constitución de la sociedad: bases para la teoría de la estructuración. Buenos Aires: Amorrortu Editores; 1995.

35. Habermas J. Teoría de la acción comunicativa I. Madrid: Taurus; 1999.

36. Norbert E. O processo civilizador. v. 1. Rio de Janeiro: Jorge Zahar; 1994.

37. Foucault M. El nascimiento de la clínica. México DF: Siglo XXI; 1972.

38. Betalanfy LV. Teoria geral dos sistemas. Petrópolis: Editora Vozes; 1973.

39. Atlan H. Entre o cristal e a fumaça. Rio de Janeiro: Zahar; 1979.

40. Prigogine I. The end of certainty: time, chaos, and the new laws of nature. New York: Free Press; 1997.

41. Minayo MCS, Assis SG, Deslandes SF, Souza ER. Possibilidades e dificuldades nas relações entre Ciências Sociais e epidemiologia. Ciênc Saúde Coletiva 2003; 8:97-107.

Recebido em 10/Jul/2012

Aprovado em 23/Jul/2012 